\title{
Play Skills in Toddlers with Autism Spectrum Disorder within Their Natural Environments
}

Jillian MP ${ }^{1 *}$, Miller $\mathrm{AR}^{2}$ and Dominguez $\mathbf{S}^{3}$

${ }^{1}$ Department of Psychology, St. Mary's University San Antonio, USA

${ }^{2}$ Department of Biology, St. Mary's University, USA

${ }^{3}$ Department of Psychology, St. Mary's University, USA

\begin{abstract}
Play allows toddlers to exercise various skills. However not all toddlers, like those diagnosed with autism spectrum disorder (ASD), engage in developmentally appropriate play. Thus, it is important to investigate play given assessment of and treatment for ASD that often occurs in play environments. This study assessed mothers' reported play of toddlers with ASD ( $n=3 ; M_{2 e}=26.5$ months) in their natural environments while enrolled in an intervention program. Toddlers play was coded using five play categories. Results showed no significant differences in toddlers' engagement in play categories; however, frequencies within play categories varied. This research is important for its insight of play in ASD for therapists and caregivers, and identifying play competencies to best conduct play based therapies.
\end{abstract}

Keywords: Play; Autism spectrum disorder; Toddlers; Natural environments

\section{Introduction}

Play is a natural proclivity for toddlers, and it is a platform for which skills are learned and practiced [1-4]. For example, toddlers can learn to take turns, communicate with others, practice fine and gross motor skills, and utilize their imaginations all within the context of play. However, not all toddlers engage in appropriate play behaviors (e.g., exhibiting repetitive behaviors) nor develop the ability to engage in complex, age-expected play skills (e.g., lack pretend play).

In particular, for one to be diagnosed with autism spectrum disorder (ASD), she is likely to exhibit impairment in symbolic or imaginative play - as described within the social communication and interaction criterion of ASD [5]. Many studies have examined play in children with ASD, which have shown children's play skills to be limited and restricted $[6,7]$ to the extent that children with ASD were once thought to have "impoverished" play skills [8-10]. Examples of such impoverished play skills include difficulties engaging in symbolic play and participating in fewer functional play activities compared to their peers [11-13]. Given these formerly identified deficits, play skills in toddlers with ASD is important for study especially because assessment measures used to diagnose ASD and intervention models used for treatment of ASD often occur within play environments [14-17].

Provided this information, less reports exist on play competencies and play patterns in toddlers with ASD. Therefore, this study investigated play behaviors in toddlers with ASD within their natural environments to better understand what types of play toddlers with ASD engage. Furthermore, because play is a complex unit and play behaviors in ASD can present atypically it is necessary to consider existing stages and categories of play that have been explored in children with both typical and atypical development.

Play is multifarious and known to follow a sequential order, commencing with simple play skills and progressively evolving into more complex play skills; thus, it is important to examine how play skills are categorized along this continuum. In other words, play skills are first relatively basic in display and often become more detailed. This has inspired former researchers to create discrete play categories that capture the progression of play beginning in infancy [18]. Investigated peer sociability in the context of play and suggested a linear approach of play with the following categories: nonsocial, parallel, associative, and cooperative play. Similarly Fantuzzo et al. [19] studied play in maltreated and non-maltreated preschool children, which they measured children's play through the following categories: nonplay, solitary play, social attention play, and interactive play. These researchers' framework of play suggest that play is initially isolated and becomes more interactive by jointly and actively involving others.

Another perspective of play categories was presented by Valentino et al., which they highlighted seven categories of play. They proposed children begin with nonplay (e.g., keeping to oneself, not interacting with objects or others) and progress toward pretend-other These categories were adapted by former works [20,21] where these researchers examined infants' free play and sensorimotor intelligence through pretend play, respectively.

In addition, Lifter generated the Developmental Play Assessment which was designed to assess play skills within play-based interventions for children with/at-risk-for developmental disabilities and/or delays. In particular, this play assessment (i.e., DPA) captured 14 stages of play beginning with indiscriminate actions (e.g., mouthing all objects) and ending with thematic fantasy play (e.g., pretending to be a princess). Other researchers have also examined play categories within playbased therapies for ASD. Ingersoll and Dvortcsak addressed the sequence of play through 10 categories beginning with exploratory play and progressing to socio dramatic play. For example, they considered exploratory play as throwing a block whereas socio dramatic play involved playing house. Their 10 categories of play are used for

*Corresponding author: Jillian MP, PhD, Department of Psychology, St. Mary's University, San Antonio, TX, USA, Tel: (210) 436-3314; E-mail: jpierucci@stmarytx.edu Received October 25, 2017; Accepted January 01, 2018; Published January 10, 2018

Citation: Jillian MP, Miller AR, Dominguez S (2018) Play Skills in Toddlers with Autism Spectrum Disorder within Their Natural Environments. J Ment Disord Treat 4: 151. doi:10.4172/2471-271X.1000151

Copyright: $\odot 2018$ Jillian MP, et al. This is an open-access article distributed under the terms of the Creative Commons Attribution License, which permits unrestricted use, distribution, and reproduction in any medium, provided the original author and source are credited. 
developing and implementing children's treatment plans in Project ImPACT a parent-mediated intervention curriculum for young children with ASD. Moreover, this intervention program (i.e., Project ImPACT) identifies children's play abilities, emphasizing how important play is during treatment for ASD and illuminates the commonness of young children's therapies occurring in play environments.

Overall, these aforementioned, sequential categories of play created by various researchers support the notion that play is less complicated in its early stages and requires more adept, competent skills in its later stages. Additionally, much of the descriptions of the play categories overlap across the various researchers showing that play is dimensional.

Therefore, the purpose of the current study, while acknowledging many existing play categories, play skills of toddlers with ASD were categorized into five types of play. These play categories were inspired by former researchers [22] In other words, the identified play categories from previous research were synthesized and organized into the following: (1) motor, (2) constructive, (3) cognitive, (4) social, and (5) imaginative play. See Method section and Table 1 for descriptions and examples of these five play categories.

\section{Purpose of Current Study}

Recognizing that assessment measures used for ASD diagnoses and intervention models used for ASD treatment often occur within play environments [23] it is important to consider play behaviors naturally exhibited by toddlers with ASD. Even more so, play is an essential activity that fosters necessary skills such as social and communication skills [24]. Therefore, the goal of the present study was to explore the types of play toddlers with ASD participate in within their natural environments; in order to provide insight to therapists and caregivers and best conduct play-based therapies.

\section{Method}

\section{Design}

The current study was a(n) single-subject, A-B intervention design. In other words, all participants started Project ImPACT baseline sessions (i.e., A) simultaneously and continued onward with intervention sessions (i.e., B) once baseline sessions were completed.

\section{Participants}

Participants were mothers $(\mathrm{M}=30$ years, $\mathrm{SD}=5.29$; range (26-36) and their toddlers diagnosed with ASD ( $n=3 ; 2$ males and 1 female; $\mathrm{M}=26.5$ months, $\mathrm{SD}=3.8$ at commencement of study), which were recruited from a University ASD Clinic in the southeast region of the United States. Selection and recruitment occurred after two-day diagnostic evaluations were conducted at the clinic. In particular the diagnostic battery of measures included the Autism Diagnostic Observation Schedule [24], Childhood Autism Rating Scale-Second Edition [25], Autism Diagnostic Interview-Revised, Mullen Scales of Early Learning [26] and Vineland Adaptive Behavior Scales-Second Edition [27]. The ASD diagnoses for the recruited toddlers were made by a multidisciplinary team (i.e., licensed clinical psychologist, speechlanguage pathologist, psychology graduate student, and paediatrician) based on the DSM-IV, provided this was the recent edition of the DSM at the time of diagnoses.

\section{Procedure}

All toddlers assented to participate in the study (e.g., showed signs of compliance) while mothers signed informed consents. Participants attended group sessions at the University ASD clinic two days each week for nine consecutive weeks (i.e., $\mathrm{n}=5$ baseline sessions, $\mathrm{n}=12$ intervention sessions). Each session lasted approximately 1.5 hours. The parent-group sessions occurred in a conference room where the adult examiner conducted lessons using the Project ImPACT intervention curriculum.

Simultaneously, six trained undergraduate research assistants were with the toddlers in a large therapy room. Two research assistants were assigned to each toddler where they provided individual therapy using the Project ImPACT intervention curriculum. Project ImPACT, often used for children with ASD, targets equipping parents with appropriate strategies to assist their children's developmental delays. In particular, this intervention aims to increase four core skills: (1) social engagement, (2) language, (3) imitation, and (4) play. At the conclusion of each parent-group session with the adult examiner, mothers individually implemented the intervention strategies from Project ImPACT with their toddlers in the separate clinic rooms. Immediately following, the adult examiner provided individual feedback to and coaching for each mother about her implementation of the learned strategies from Project ImPACT.

In conjunction with mothers attending parent-group sessions at the University clinic, it was also expected that mothers continued to use these intervention strategies in their natural environments (e.g., home) for the duration of the study. Thus while in their natural environments, mothers kept daily play logs documenting the play-based activities in which their toddlers engaged. Specifically on these play logs, mothers documented: (1) the types of play they engaged in with their toddlers/ observed their toddlers participating in and (2) the duration of engaging in such activities. The adult examiner collected the daily play logs at the beginning of each session of Project ImPACT, which were later coded by trained, undergraduate research assistants as outlined below.

\section{Coding}

From the mother-reported daily documentation of their toddlers' play engagements, play categories were created. These categories were inspired by previous researchers Thus for the purpose of the current study, the following categories were created and coded accordingly: (1) motor, (2) constructive, (3) cognitive, (4) social, and (5) imaginative play. Motor play included activities such as: chase, walking outside, and catch. Constructive play included activities such as: clean up and daily routines like bathtime. Cognitive play included activities such as: books and puzzles. Social play included activities such as such as : bubbles and talking about family photos. Lastly, imaginative play included activities such as: pretending to be animals or a father. Uncategorized play $(n=4)$ included vague descriptions lacking detail that did not warrant a specific category such as: taking pictures and playing with cellular devices. Table 1 that includes detailed examples for each of the five play categories.

\section{Results}

\section{Interrater reliability}

Interrater reliability between the two coders was calculated using percent of agreement. Two trained, undergraduate research assistants independently coded each play activity as reported by mothers into its appropriate play category. Additionally, the coders were blind to the participants' sessions (i.e., baseline or intervention sessions) to prevent biases. At the conclusion of their coding, the adult examiner resolved the $25.44 \%$ disagreement ( $n=144$ of 566) between the two blind coders. However when resolving the disagreements, the examiner agreed with 
one of the original coders $100 \%$ ( $n=144$ of 144$)$ during the second round of coding. Overall, the percent of play category agreement by the two trained, blind coders was $74.56 \%$ on all the mothers' reported play activities of the toddlers $(n=566)$. These coded play categories were used in subsequent data analyses.

The main objective was to explore the types of play toddlers engaged in as observed and reported by their mothers. From the natural environment play activities documented during the five baseline sessions $(n=181)$, toddlers' play activities were $19.1 \%$ motor, $24.2 \%$ constructive, $19.7 \%$ cognitive, $35.4 \%$ social, and $1.7 \%$ imaginative. Figure 1 displays the percentages of the types of play engaged in by toddlers during baseline sessions. From the natural environment play activities documented during the 10 intervention sessions $(n=385)$, toddlers' play activities were $17.8 \%$ motor, $26.2 \%$ constructive, $20.2 \%$ cognitive, $34.6 \%$ social, and $1.0 \%$ imaginative. Figure 2 displays the percentages of the types of play engaged in by toddlers during intervention sessions. Overall for both baseline and intervention sessions combined $(n=566)$, toddlers' play activities within their natural environments were $18.2 \%$ motor, $25.6 \%$ constructive, $20.0 \%$ cognitive, $34.9 \%$ social, and $1.3 \%$ imaginative. Figure 3 displays the overall percentages of the types of play engaged in by toddlers during baseline and intervention sessions combined.

To further assess if there were significant differences in the types of play engaged in by toddlers during baseline sessions compared to intervention sessions, an independent samples t-test was conducted. Results showed no differences in the types of play engaged in during

\begin{tabular}{|c|c|}
\hline Play Category & Examples \\
\hline Motor & $\begin{array}{c}\text { Walking or running outside } \\
\text { Playing chase or catch } \\
\text { Picking blueberries } \\
\text { Swimming }\end{array}$ \\
\hline Constructive & $\begin{array}{c}\text { Breakfast, lunch, dinner times } \\
\text { Morning and bedtime routines } \\
\text { Cooking meals } \\
\text { Cleaning up toys }\end{array}$ \\
\hline Cognitive & Story time \\
& Doing puzzles \\
\hline Social & $\begin{array}{c}\text { Conversations with family } \\
\text { Bubbles with family }\end{array}$ \\
& Discussing family members in photos \\
\hline Imaginative & Acting like a father on golf course \\
& Pretending to be animals \\
\hline
\end{tabular}

Table 1: Examples of activities for each play category.

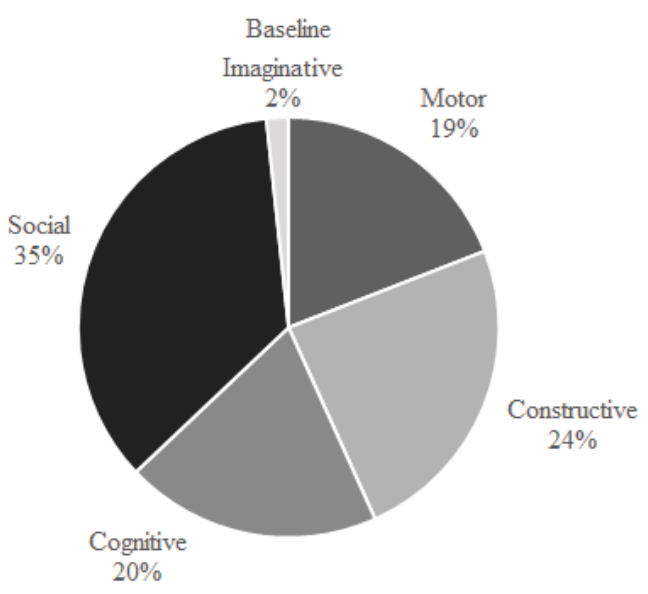

Figure 1: Baseline sessions.

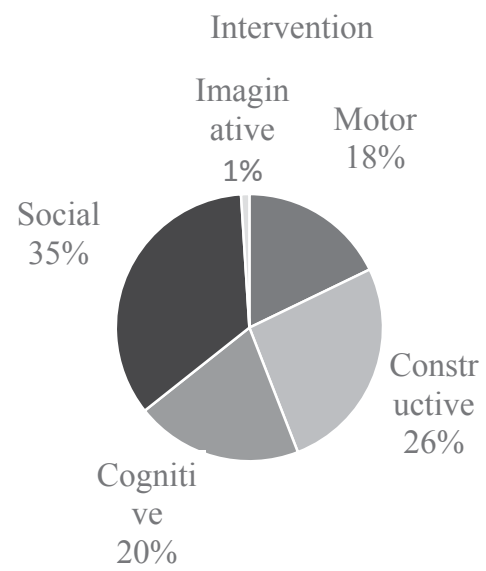

Figure 2: Intervention sessions.

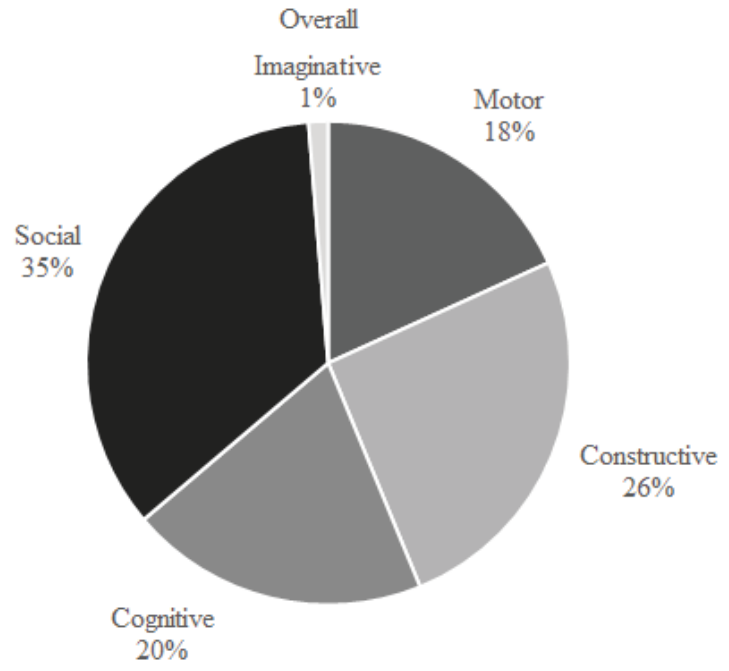

Figure 3: Overall percentages

baseline Sessions compared to intervention sessions, $t(565)=0.153$, $\mathrm{p}=\mathrm{ns}$. In other words, toddlers continued to participate in all play categories between each session while in their natural environments.

However for all toddlers, frequencies for each type of play showed various patterns. Therefore, Simulation Modeling Analysis (SMA) was conducted to assess variation in participating in specific types of play between each session. In particular, SMA compared each play category's average frequency of baseline sessions to the average frequency of intervention sessions. Motor play remained constant from baseline $(M=6.8)$ to intervention $(M=6.8)$ showing no significant change in toddlers' motor activities $(\mathrm{r}=0.0, \mathrm{p}=\mathrm{ns})$. Constructive play increased from baseline $(M=8.6)$ to intervention $(M=10.0)$ although there was no significant change in toddlers endorsement of constructive activities $(\mathrm{r}=0.122, \mathrm{p}=\mathrm{ns})$. In addition, cognitive play increased from baseline $(M=7.0)$ to intervention $(M=7.7)$ although there was no significant change in toddlers' cognitive activities $(\mathrm{r}=109, \mathrm{p}=\mathrm{ns})$. Social play also increased from baseline $(M=12.6)$ to intervention $(M=13.2)$, however toddlers did not show significant changes in endorsement of social activities $(\mathrm{r}=0.049, \mathrm{p}=\mathrm{ns})$ Lastly, imaginative play decreased from baseline $(\mathrm{M}=0.6)$ to intervention $(\mathrm{M}=0.4)$ although there was no significant change in toddlers endorsement of imaginative activities 
$(\mathrm{r}=-0.189, \mathrm{p}=\mathrm{ns})$. Combining all play categories, engagement in play increased from baseline $(M=35.6)$ to intervention $(M=38.1)$ although the increase in frequencies was not statistically significant $(r=0.073$, $\mathrm{p}=\mathrm{ns})$. In summary, results showed motor play remaining consistent, imaginative play decreasing, and other types of play increasing (i.e., constructive, cognitive, social) from baseline to intervention sessions (Table 2). Displays the frequencies of the types of play engaged in by toddlers during baseline and intervention sessions.

\section{Discussion}

The purpose of the current, exploratory study was to investigate the types of play that toddlers with ASD naturally engage. This research spanning across nine weeks showed that toddlers engaged in similar types of play supporting no significant variation in their patterns of play. This finding of maintaining play skills is interesting given children with ASD have shown atypical patterns of development such as skill regression [28]. Over and above these toddlers' play skills not conveying significant decrease or regression, toddlers continued to endorse each type of play relatively consistently between each baseline and intervention session. Meaning, there was no significant fluctuation in their play patterns as reported by mothers. Potential explanations in their play consistencies is that their play was only documented for nine weeks and also that mothers were the sole observers reporting on their toddlers play, which might present unintentional biases. Another noteworthy finding was that Project ImPACT remains an effective intervention curriculum specifically shown in its unique ability to maintain toddlers' play skills (i.e., no draconian regression). Thus, continued consideration of implementing Project ImPACT for young individuals with ASD is appropriate.

Knowingly so, play is an important part of childhood development, in which many interventions are play-based In particular, one core component of the intervention utilized in this study (i.e., Project ImPACT) was the focus on play. Interestingly, toddlers showed, as reported by mothers, more participation in complex types of play (e.g., constructive, cognitive, and social) as reflected in the average frequencies during intervention sessions compared to baseline sessions. With sensitive interpretation, this suggests that that toddler with ASD are capable of engaging in complex play behaviors and increasing frequencies of play behaviors over time, which corroborates previous alike findings. Furthermore, many children with ASD experience difficulties engaging in complex play; however, these results showed that approximately one-third of toddlers play was categorized as social play. This is encouraging given social deficits are a d diagnostic criteria of ASD thereby focusing on improving toddlers' social play skills could optimally lead to better outcomes for individuals with ASD Interestingly, these data showed a decrease, although not statistically significant, in toddlers' imaginative play activities. Because of the known benefits that are facilitated by imaginative play in children with

\begin{tabular}{|l|c|c|c|}
\hline Play Categories & Baseline & Intervention & Total \\
\cline { 2 - 4 } & Sessions 1-5 & Sessions 6-15 & Sessions 1-15 \\
\hline Motor & 34 & 68 & 102 \\
\hline Constructive & 43 & 100 & 143 \\
\hline Cognitive & 38 & 81 & 119 \\
\hline Social & 63 & 132 & 195 \\
\hline Imaginative & 3 & 4 & 7 \\
\hline
\end{tabular}

Note: The baseline phase had 5 sessions while the intervention phase had 12 sessions; however, mothers only submitted play logs for their toddlers during 10 of 12 the intervention sessions.

Table 2: Frequencies of play categories for baseline (Sessions 1-5) and intervention (Sessions 6-15). typical development this study highlights the need for stimulating and scaffolding imaginative play in children with ASD.

Beyond these enlightening findings, this study has various limitations. First, the time required of mothers to document their toddlers daily play was straining on mothers' already demanding schedules. During many sessions when mothers submitted their daily play logs to the adult examiner, mothers reported they did not document all the play activities in which they engaged with and observed their toddlers participating. Thus, these data were a conservative report of the toddlers play. One explanation for their under-reporting of play activities was that mothers stated they spent less time documenting toddlers play on the daily play logs and instead utilized the time to engage with their toddlers and implement their learned strategies from Project ImPACT. Another limitation was that the study's data were based solely on mothers' observations. It has been shown that parental reports can vary when examining social skills in children and adolescents with ASD thereby suggesting that maternal observations and reports of other skills such as play skills could also vary and warrant corroboration from other informants (e.g., adult examiner, clinician). In contrast, and encouragingly, it has also been shown that mothers and classroom educators observed similar play behaviors in children with ASD [29,30]. Lastly, these findings are limited by the sample size ( $\mathrm{n}=3$ toddlers); however, small samples are not unique to ASD research Alongside limitations of this study, this study contains various strengths and offers contributions to existing literature about play. First, this study uniquely contributes to understanding play in toddlers with ASD by mothers' reports from observations in their natural environments. It is known that play can present differently in various settings therefore this study provides descriptions of play in toddlers' natural environments from the maternal perspective. Additionally, this study is of few studies to examine play in toddlers with ASD whereas other literature has heavily focused on preschool aged and older children with ASD [31,32]. This study also enhances existing literature on play by synthesizing existing play categories noted by previous researchers.

Future research could expand on longitudinal assessment of toddlers play [33] by investigating play patterns and behaviors over several months. Additionally, other studies assessing play could also use the newly created and synthesized play.

Categories offered in this study. For example, future researchers could assess play patterns in samples with typical and atypical development using the provided coding schema, whether investigating the categories independently or conjunctively [34]. Lastly, future research should consider designs with multiple informants and various settings for play observations to enhance perspectives of toddlers play.

Overall, this research provides initial data of play in toddlers with ASD. It is important because it expands the understanding of how play presents in toddlers with ASD and has implications for service providers and caregivers. For example, this study can provide insight for play-based therapies to focus on various types of play, given toddlers with ASD have shown to be competent, thereby propelling children with ASD to display optimal developmental and social benefits experienced in play environments. In addition, this study also supports that caregivers and interventionists should meet children at their current play skills and facilitates more complex play via modelling. In summary, this research is important because it can inform therapists and caregivers of play patterns in ASD and shape implementation of play-based therapies [35-46]. 
Citation: Jillian MP, Miller AR, Dominguez S (2018) Play Skills in Toddlers with Autism Spectrum Disorder within Their Natural Environments. J Ment Disord Treat 4: 151. doi:10.4172/2471-271X.1000151

\section{Compliance with Ethical Standards}

All authors declare she has no conflicts of interest with this research project. All procedures performed in this study that involved human participants were in accordance with the ethical standards of the institutional and/or national research committee and with the 1964 Helsinki declaration and its later amendments or comparable ethical standards. Informed consent and assent were obtained from all individual participants included in the study.

\section{References}

1. Pierucci JM, O'Brien CT, Mclnnis MA, Gilpin AT, Barber AB (2014) Fantasy orientation constructs and related executive function development in preschool. International Journal of Behavioral Development 38: 62-69.

2. Pierce HK (2011) Exploratory, functional, and symbolic play behaviors of toddlers with autism spectrum disorders. (Unpublished doctoral dissertation). Florida State University, Tallahassee.

3. Ingersoll B, Dvortcsak A (2010) Teaching social communication: A practitioner's guide to parent training for children with autism. New York: Guilford Press.

4. Rogers SJ, Dawson G (2009) Early start Denver model for young children with autism: Promoting language, learning, and engagement. New York: Guilford Press.

5. American Psychiatric Association (2000) Diagnostic and Statistical Manual of Mental Disorders DSM-IV-TR.

6. Mundy P, Sigman M, Ungerer J, Sherman T (1986) Defining the social deficits of autism: The contribution of non-verbal communication measures. Journal of Child Psychology and Psychiatry 27: 657-669.

7. Ingersoll B, Wainer A (2013) Initial efficacy of Project ImPACT: A parentmediated social communication intervention for young children with ASD. Journal of Autism and Developmental Disorders 43: 2943-2952.

8. Wing L, Gould J, Yeates SR, Brierley L (1977) Symbolic play in severely mentally retarded and in autistic children. Journal of Child Psychology \& Psychiatry 18: 167-178.

9. Riguet CB, Taylor ND, Benaroya S, Klein LS (1981) Symbolic play in autistic, Down's, and normal children of equivalent mental age. Journal of Autism and Developmental Disorders 11: 439-448.

10. Ungerer JA, Sigman M (1981) Symbolic play and language comprehension in autistic children. Journal of the American Academy of Child Psychology 20: 318-337.

11. Jarrold C, Boucher J, Smith PK (1996) Generativity deficits in pretend play in autism. British Journal of Developmental Psychology 14: 275-300.

12. Wetherby AM, Watt N, Morgan L, Shumway S (2007) Social communication profiles of children with autism spectrum disorders late in the second year of life. Journal of Autism and Developmental Disorders 37: 960-975.

13. Williams E, Reddy V, Costall A (2001) Taking a closer look at functional play in children with autism. Journal of Autism and Developmental Disorders 31: 67-77.

14. Kasari C, Gulsrud AC, Wong C, Kwon S, Locke J (2010) Randomized controlled caregiver mediated joint engagement intervention for toddlers with autism. Journal of Autism and Developmental Disorders 40: 1045-1056.

15. Rogers SJ, Dawson G (2009) Early start Denver model for young children with autism:Promoting language, learning, and engagement. New York: Guilford Press.

16. Wetherby AM, Woods $\mathrm{J}$ (2006) Early social interaction project for children with autism spectrum disorders beginning in the second year of life: A preliminary study. Topics in Early Childhood Special Education 26: 67-82.

17. Wetherby AM, Guthrie W, Woods J, Schatschneider C, Holland RD, et al (2014) Parent-implemented social intervention for toddlers with autism: An RCT. Pediatrics 134: 1084-1093.

18. Parten M (1932) Social participation among preschool children. Journal of Abnormal and Social Psychology 27: 243-269.

19. Fantuzzo J, Sutton-Smith B, Atkins M, Meyers R, Stevenson H, et al. (1996) Community-based resilient peer treatment of withdrawn maltreated preschool children. Journal of Consulting and Clinical Psychology 64: 1377-1386.
20. Belsky J, Most RK (1981) From exploration to play: A cross sectional study of infant free play behavior. Developmental Psychology 17: 632

21. Nicholich LM (1977) Beyond sensorimotor intelligence: Assessment of symbolic maturity through analysis of pretend play. Merrill-Palmer Quarterly: Journal of Developmental Psychology 23: 92-94.

22. Vismara LA, Colombi C, Rogers S (2010) Can one hour per week of therapy lead to lasting changes in young children with autism? Autism 13: 93-115.

23. Wolfberg $P$ (2009) Play and imagination in children with autism (2ndedn), New York, NY: Teachers College Press.

24. Gleason T (2002) Social provisions of real and imaginary relationships in early childhood. Developmental Psychology 38: 979-992.

25. Schopler E, Van Bourgondien ME, Wellman GJ, Love SR (2010) Childhood Autism Rating Scale. Los Angeles, CA: Western Psychological Services.

26. Rutter M, LeCouteur A (2003) Autism Diagnostic Interview - Revised. Los Angeles, CA: Western Psychological Services.

27. Sparrow SS, Cicchettim DM, Balla DA (2006) Vineland Adaptive Behavior Scales - Second Edition. San Antonio: Pearson's Clinical Assessment.

28. Ozonoff S, Heung K, Byrd R, Hansen R, Hertz-Picciotto I (2008) The onse of autism: Patterns of symptom emergence in the first years of life. Autism Research 1: 320-328.

29. Lillard AS, Lerner MD, Hopkins EJ, Dore RA, Smith ED, et al. (2012) The impact of pretend play on children's development: A review of the evidence. Psychological Bulletin 139: 1-34.

30. Holmes E, Willoughby T (2005) Play behaviour of children with autism spectrum disorders. Journal of Intellectual and Developmental Disabilities 30: 156-164.

31. Bruckner CT, Yoder P (2007) Restricted object use in young children with autism. Autism 11: 161-171.

32. Toth K, Munson J, Meltzoff AN, Dawson G (2006) Early predictors of communication development in young children with autism spectrum disorder: Joint attention, imitation, and toy play. Journal of Autism and Developmental Disorders 36: 993-1005.

33. Rutherford MD, Young GS, Hepburn S, Rogers SJ (2007) A longitudinal study of pretend play in autism. Journal of Autism and Developmental Disorders 37: 289-302.

34. Honey E, Leekam S, Turner M, McConachie H (2007) Repetitive behavior and play in typically developing children and children with autism spectrum disorders. J Autism Dev Disord 37: 1107-1115.

35. Baron Cohen S (1987) Autism and symbolic play. British Journal of Developmental Psychology 5: 139-148.

36. Berkson G, Tupa M (2000) Early development of stereotyped and self-injurious behaviours Journal of Early Intervention 23: 1-19.

37. Bodfish JW, Symons FJ, Parker DE, Lewis MH (2000) Varieties of repetitive behaviour in autism: Comparisons to mental retardation. Journal of Autism and Developmental Disorders 30: 237-243.

38. Bruckner CT, Yoder $P$ (2007) Restricted object use in young children with autism: definition and construct validity.. Autism 11: 161-171.

39. Charman T, Baron-Cohen S, Swettenham J, Baird G, Cox A, et al. (2000) Testing joint attention, imitation, and play as infancy precursors to language and theory of mind. Cognitive Development 15: 481-498.

40. Evans DW, Leckman JF, Carter A, Reznick JS, Henshaw D, et al. (1997) Ritual habit, and perfectionism: the prevalence and development of compulsive-like behavior in normal young children. Child Development 68: 58-68.

41. Happe F (1994) Autism: An introduction to psychological theory. East Sussex Psychology Press.

42. Koegel RL, Schreibman L, Britten KR, Burke JC, O'Neill RE (1982) A comparison of parent training to direct child treatment. In: Koegel RL, Rincover A, Egel AL (eds.) Educating and Understanding Autistic Children. San Diego CA: College-Hill.

43. Matson JL, Worley JA, Kozlowski AM, Chung KM, Jung W, et al. (2012) Cross cultural differences of parent reported social skills in children with autistic disorder: An examination between South Korea and the United States of America. Research in Autism Spectrum Disorders 6: 971-977. 
Citation: Jillian MP, Miller AR, Dominguez S (2018) Play Skills in Toddlers with Autism Spectrum Disorder within Their Natural Environments. J Ment Disord Treat 4: 151. doi:10.4172/2471-271X.1000151

Page 6 of 6

44. Naber FBA, Bakermans-Kranenburg MJ, van IJzendoorn MH, Swinkels SHN, Buitelaar JK, et al. (2008) Play behavior and attachment in toddlers with autism. Journal of Autism and Developmental Disorders 38: 857-866.

45. Wetherby AM, Woods J, Allen L, Cleary J, Dickinson H, et al. (2004) Early indicators of autism spectrum disorders in the second year of life. Journal of Autism and Developmental Disorders 34: 473-493.

46. Wing $L$ (1996) Autistic spectrum disorders. 312: 327 